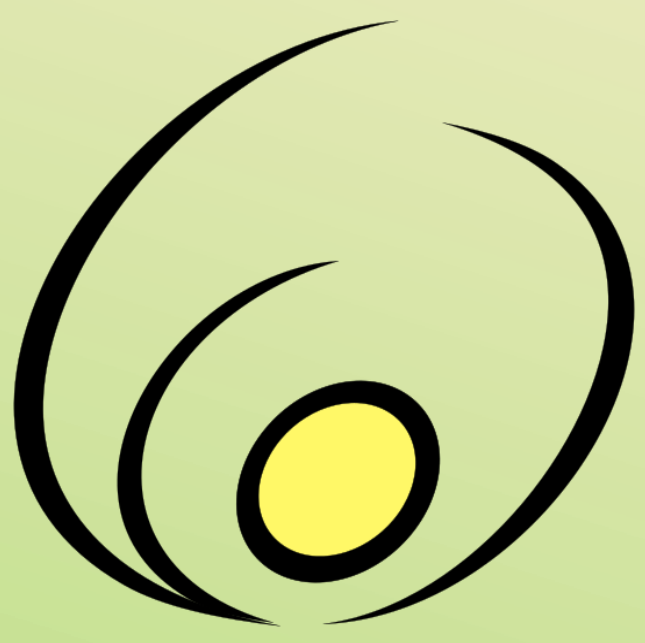

Fórum de

\section{Pró-Reitores}

\section{de Extensão}

das Instituições

Públicas de

\section{Educação Superior}

\section{Brasileiras}

Open access $\delta$ free available online

\title{
Educação higiênico-sanitária dos feirantes do Mercadão 2000 e Feira do Pescado em Santarém-PA
}

\author{
Talita Monteiro de Souza ${ }^{1}$; Hérlon Mota Atayde ${ }^{2}$
}

Resumo: As feiras de pescado de Santarém são importantes para comercialização de diversos produtos, mas apresentam graves problemas devido ao comprometimento da qualidade dos mesmos, com potencial risco aos feirantes e consumidores. Como solução, sugere-se a conscientização do feirante sobre as condições higiênico-sanitárias adequadas. Portanto, essa ação extensionista buscou conscientizar feirantes sobre a melhoria da qualidade do pescado ofertado em feiras de Santarém e foi executada em três etapas. Nas etapas 1 e 3 foram efetuados os diagnósticos (preliminar e pósinstrução) das condições higiênico-sanitárias das feiras Mercadão 2000 e Feira do Pescado, por meio de dois formulários aplicados simultaneamente, sendo um para registro das análises do pesquisador (baseado na legislação brasileira vigente) e outro para os feirantes; na etapa 2, cursos foram aplicados aos feirantes, com instruções sobre essas condições higiênico-sanitárias das feiras comparadas à legislação vigente. Nos diagnósticos foram entrevistados 40 feirantes. Na etapa 1, entre outras constatações, muitas roupas utilizadas estavam inadequadas $(92,5 \%)$; nem todos realizavam a lavagem das mãos corretamente $(47,5 \%)$ e a maioria dos equipamentos e utensílios era inadequada à atividade. Na etapa 2, contou-se com a participação de 46 feirantes. Na etapa 3, comparada à etapa 1 , foram observadas algumas modificações positivas, em conformidade com a legislação vigente, nos itens roupas utilizadas $(40 \%)$ e na higiene das mãos $(82,5 \%)$, entre outros. Portanto, ações educativas e de conscientização são soluções para a maioria dos problemas encontrados nas feiras de Santarém, associadas a adequações na infraestrutura pelo órgão municipal responsável.

Palavras-chave: Manipulação, Peixes, Sanidade, Norte

\footnotetext{
${ }^{1}$ Engenheira de Pesca - Instituto de Ciências e Tecnologia das Águas (ICTA) - Universidade Federal do Oeste do Pará (UFOPA) - Av. Mendonça Furtado, n² 2946, Bairro Fátima, Santarém - PA, CEP 68040-050. talita.monteirods@gmail.com

2 Docente do Bacharelado em Engenharia de Pesca - ICTA - UFOPA - Av. Mendonça Furtado, $n^{\circ} 2946$, Bairro Fátima, Santarém - PA, CEP 68040-050; e-mail: herlon.atayde@ufopa.edu.br (autor para correspondência)
} 
Hygienic-sanitary education of the market traders at the Mercadão 2000 Fair and the Fish

\author{
Fair in Santarém, Brazil
}

\begin{abstract}
The fish fairs of Santarém, Pará State, Brazil, are important for the marketing of various products but present serious problems due to the compromise between the quality thereof and the potential risk to the market traders and the consumers. As a solution, raising awareness among the market traders about adequate hygienicsanitary conditions is suggested. Therefore, this extension action sought to raise awareness among the market traders about the improvement of the fish quality offered at fairs in Santarém and was carried out in three stages. In stages 1 and 3, the diagnoses (preliminary and post-instruction) of the hygienic-sanitary conditions of the Mercadão 2000 and the Fish Fair were carried out in two forms applied simultaneously, one for recording the researcher's analyses (based on current Brazilian legislation) and another for the market traders; in stage 2, courses were given to the market traders, with instructions about these hygienic-sanitary conditions of the fairs compared to the current legislation. In the diagnoses, 40 market traders were interviewed. In stage 1, among other findings, many of the clothes used were inadequate (92.5\%); not all performed hand-washing correctly (47.5\%) and most of the equipment and utensils were unsuitable for the activity. 46 market traders participated in stage 2 . In stage 3, compared to stage 1, some positive changes were observed, in accordance with the current legislation, in the items of clothing used (40\%) and hand hygiene (82.5\%), among others. Therefore, educational and awareness-raising actions are solutions to most of the problems encountered at the fairs in Santarém, associated with adjustments in the infrastructure by the municipal agency responsible.
\end{abstract}

Keywords: Handling, Fish, Health, North

\title{
Educación higiénico-sanitaria de los feriantes del "Mercadão 2000" y Feria del Pescado en
} Santarém, Brasil

Resumen: Las ferias de pescado de Santarém, Estado de Pará, Brasil, importante para la comercialización de diversos productos, pero tiene serios problemas debido al deterioro de la calidad de estos y por tanto representando un riesgo potencial para los feriantes y los consumidores. Como solución, se sugiere generar conciencia en el feriante sobre las adecuadas condiciones higiénico-sanitarias. Por lo tanto, esta acción de extensión buscaba elevar la conciencia de los feriantes sobre la mejora de la calidad del pescado que se ofrece en las ferias de Santarém, la cual se completó en tres etapas. En las etapas 1 y 3 se hicieron los diagnósticos (preliminar y posterior a la instrucción) de las condiciones higiénico-sanitarias de las ferias del "Mercadão 2000" y Feria del Pescado a través de dos formularios aplicados de forma simultánea, una para registro de análisis del investigador (en base a la legislación brasileña actual) y una para los feriantes; en la etapa 2, los cursos se aplicaron a los feriantes, con instrucciones sobre las condiciones higiénico-sanitarias de las ferias en comparación con la legislación vigente. En el diagnóstico se entrevistó a 40 feriantes. En la etapa 1, entre otros hallazgos, mucha de la ropa utilizada era inadecuada (92,5\%); no todos se lavaban las manos correctamente $(47,5 \%)$ y la mayoría de los equipos y utensilios era inadecuados para la actividad. En la etapa 2, se contó con la participación de 46 feriantes. En la etapa 3, en comparación con la etapa 1, se observaron algunos cambios positivos en conformidad con la legislación actual, en los ítems, ropas utilizadas (40\%) y la higiene de manos $(82,5 \%)$, entre otros. Por lo tanto, acciones de educación y de creación de conciencia son soluciones para la mayoría de los problemas encontrados en las ferias de Santarém, junto con ajustes en la infraestructura por el órgano municipal responsable.

Palabras-clave: Manipulación, Pescado, Sanidad, Norte

\section{Introdução}

A feira é importante no processo de comercialização e trocas inter-regionais, principalmente nas regiões Norte e Nordeste do Brasil, representando fundamental meio de sobrevivência para as pequenas cidades dessas regiões (ALMEIDA; PENA, 2011). Comumente, apresentam condições de higiene inadequadas - fato comprometedor da qualidade dos produtos ofertados - além de propiciar a contaminação da matéria-prima, ambiente e manipuladores de alimento (SANTOS et al., 2014; ALCÂNTARA; KATO, 2016).

Segundo a Organização Mundial da Saúde - OMS (2002), a contaminação dos alimentos é consequência do pouco conhecimento e falta de treinamento dos manipuladores. Portanto, é fundamental que haja 
conscientização dos mesmos sobre a prática correta da manipulação de alimentos (CAMPOS et al., 2016).

Para garantir essa prática adequada, a legislação sanitária brasileira descreve que nas ofertas de serviços que realizam a manipulação, preparação, armazenamento, exposição à venda de alimentos em geral, dentre outras atividades, devem ser implementadas as Boas Práticas para Serviços de Alimentação (BRASIL, 2004).

Para o pescado há muitas referências bibliográficas demonstrando como identificar o grau de frescor e o modo mais adequado de comercialização (CAMPOS; PAIVA, 2012) e, por ser um alimento altamente perecível, exige maior fiscalização da higiene na manipulação, limpeza, transporte e conservação (YAMAMOTO; BRANCO; SANTOS, 2012).

Pesquisas junto aos frequentadores das principais feiras de Santarém apontaram que, apesar da população preferir peixe como alimento (SOUZA et al., 2015), esse não é frequentemente consumido na região devido à falta de qualidade e das péssimas condições higiênicas dos locais de venda do município (LEANDRO et al., 2015).

Além disso, Almeida et al. (2015) informam que alguns peixes ofertados nos mercados públicos de Santarém apresentaram estágio avançado de deterioração, ressaltando a necessidade dos feirantes ofertarem produtos com qualidade. Adicionalmente, a qualidade e higiene deficientes desses peixes nesse município foram ocasionadas pelas inadequações da infraestrutura das feiras, conservação e processamento pelos feirantes (BRANDÃO et al. 2014, LEANDRO et al., 2015).

No intuito de aprimorar as condições higiênico-sanitárias da Feira do Agricultor de Laranjeiras do Sul (PR), Bertolo et al. (2016) demonstraram que um diagnóstico prévio e iniciativas educativas foram eficientes. Deste modo, essa atividade extensionista teve como finalidade avaliar as condições de higiene e manipulação de peixes nas feiras Mercadão 2000 e Feira do Pescado da cidade de Santarém, bem como desenvolver um programa de treinamento e conscientização dos feirantes quanto às adequadas práticas de manipulação dos peixes ofertados.

\section{Material e Métodos}

A atividade extensionista aqui presente foi realizada em Santarém, o terceiro município mais populoso do Estado do Pará [294.580 pessoas, conforme IBGE (2010)], e contemplou os principais pontos de comercialização de peixes desse município: o Mercadão 2000 - local com diversos setores, divididos conforme o produto vendido (setor de pescado, hortaliças, carnes, roupas, entre outros); a Feira do Pescado - local estruturado para vender especificamente pescado, mas há consentimento formal para poucas bancas fornecerem hortaliças.

Os dados foram registrados em dois formulários ( $\mathrm{F} 1 \mathrm{e}$ F2), aplicados simultaneamente e previamente elaborados a partir de adaptações da Lista de Verificação da Resolução da Diretoria Colegiada - RDC - n 275,
RDC n 216 e da Portaria no 326 (BRASIL, 2003; 2004 e 1997, respectivamente). O formulário $\mathrm{F} 1$ continha questões fechadas e qualitativas (respostas possíveis "sim", "não", "não possui") em que, após observação sistemática durante 10 minutos, era registrada a perspectiva do pesquisador sobre as condições de manipulação dos peixes pelo feirante. O formulário F2, destinado aos feirantes, possuía questões abertas e qualitativas (respostas livres) no qual, durante entrevista, era obtida a perspectiva sobre as mesmas condições observadas pelo pesquisador. Ambos possuíam arguições sobre equipamentos, móveis, utensílios e higiene dos manipuladores; diferenciavam-se devido ao F2 conter linguagem mais informal, para facilitar a abordagem com o entrevistado.

Os dados foram coletados somente com feirantes $(\mathrm{N}=40$, sendo Feira do Pescado=16 e Mercadão 2000=24; amostragem por acessibilidade e equivalente a $23,5 \%$ do total) que concederam prévio consentimento à realização da pesquisa, efetuada nas seguintes etapas:

Etapa 1(E1): Nos formulários descritos acima foram registradas as condições da comercialização de peixe nas feiras, no mês de abril de 2016.

Etapa 2 (E2): Após análise sistemática dos dados da E1, os feirantes foram convidados a participar de ações educativas (junho e setembro de 2016) sobre a manipulação de pescado nessas feiras, comparando-a com a legislação vigente. Essas ações foram expostas oralmente, auxiliadas pelas ferramentas eletrônicas de apresentação (software, projetor). Também foram exibidas imagens da manipulação usual e, em paralelo, outras mostrando a conformidade com a legislação vigente. Durante essas ações, utilizando a roda de conversa, os feirantes foram instigados à participação efetiva por perguntas diretas e indiretas, visando à livre expressão, para obtenção e registro das justificativas e dificuldades de realização de algumas atitudes necessárias/exigidas pela legislação vigente para aprimoramento da venda de peixes.

Etapa 3 (E3): Foi realizada em dezembro de 2016, utilizando-se a mesma metodologia e feirantes participantes da E1.

Para análise, os dados obtidos foram transferidos para planilhas eletrônicas. As respostas qualitativas "sim", "não" e "não possui" assinalavam respectivamente "em conformidade", "em não conformidade" (com a legislação) e "não uso daquele elemento analisado"; depois, foram codificadas como dados quantitativos para submissão às ferramentas estatísticas.

Por meio da estatística descritiva, quantificou-se a perspectiva do feirante quanto à conformidade com a legislação vigente. Ainda, comparando os resultados obtidos em E2 e E3, apontou-se o efeito das ações educativas na manipulação de peixes pelos feirantes. A existência de diferenças estatisticamente significativas entre essas etapas e as determinações da legislação vigente, assim como entre as perspectivas do feirante e pesquisador sobre os elementos analisados, foram verificadas utilizando-se o Teste U (Mann-Whitney) no aplicativo BioEstat 5.3 ao nível de significância de $5 \%$. 
O uso deste teste se justificou porque os dados brutos não apresentaram distribuição normal.

\section{Resultados e Discussão}

Os resultados obtidos são abaixo apresentados da seguinte forma: primeiro, as informações quanto à E2 e, posteriormente, os dados obtidos em E1 e E3.

$\mathrm{Na}$ E2 foi desenvolvida a palestra "Controle de Qualidade e Inspeção de Produtos de Origem Pesqueira”, ministrada, em junho de 2016, aos feirantes e administradores das feiras Mercadão 2000, Feira do Pescado (ambos os alvo desta pesquisa) e Mercado Modelo (não contemplada nessa pesquisa). $\mathrm{O}$ minicurso "Estado atual da manipulação e manipuladores de peixe", aplicado, em setembro de 2016, somente aos feirantes das feiras alvo dessa pesquisa, com participação voluntária, em dois momentos: dia 14 e 26, respectivamente para a Feira do Pescado $(n=35)$ e Mercadão $2000 \quad(n=11)$, com a participação de 46 feirantes.

Os dados descritos na tabela 1 mostram que há diferença estatística significativa e favorável à qualidade da comercialização entre E1 e E3 para alguns elementos analisados.

Para os feirantes, amolador e afiador são objetos com diferentes funções na parte cortante da faca (respectivamente, afilador [afinador] e removedor de sujidades). Desta forma, para amolar as facas, fazem uso de um dos seguintes materiais: esmeril (afixado na parte rotativa de equipamento elétrico), afiador propriamente dito (chaira) e "pedra", este último um objeto rústico e difícil de higienizar.

Na E1 e E3, respectivamente, $10 \%(n=4)$ e $42,5 \%(n=15)$ dos feirantes utilizavam "afiador resistente"; $0 \%$ e $37,5 \%(\mathrm{n}=15)$ dos feirantes usavam "afiador limpo". Justifica-se a mudança em E3 devido menos feirantes utilizarem pedra, pois esta, além de não apresentar/propiciar higiene adequada, ainda possuía partes contendo retenção de ferrugem. Brasil (2003) informa que superfícies em contato com alimentos devem ser lisas, íntegras, impermeáveis, resistentes à corrosão, de fácil higienização e de material não contaminante. Portanto, determinados afiadores estavam em condições inadequadas à atividade.

Apesar de aceitáveis, tábuas plásticas utilizadas nas feiras apresentavam ranhuras e acúmulos de sujidades, além da constatação do uso de tábuas de madeira, inapropriadas conforme Brasil (2003), devido à impossibilidade de higienização/desinfecção adequada. No entanto, constataram-se entre E1 e E3 as seguintes modificações positivas no aspecto prático quanto à tábua de corte, respectivamente: $10 \%(n=4)$ e $42,5 \%(n=17)$ para "tábua de corte limpa"; $10 \%(\mathrm{n}=4)$ e $50 \%(\mathrm{n}=20)$ para "tábua de corte adequada ao trabalho", ambas diferenças estatisticamente significativas (Tabela 1).

Situação semelhante à de Santarém foi encontrada por Alcântara e Kato (2016) para Belém-PA em que a conservação de equipamentos e/ou utensílios era deficiente devido presença de áreas desgastadas, quebradas, sem revestimento adequado e/ou enferrujadas.

Tabela 1. Valores de significância $(p)$ referentes aos elementos analisados na comparação entre as duas etapas diagnósticas sobre as condições higiênico-sanitárias das feiras livres de Santarém.

\begin{tabular}{|c|c|}
\hline Elementos Analisados & Valor de $p$ \\
\hline Balança limpa & 0,8415 \\
\hline Balança funcionando & 0,8415 \\
\hline Freezer limpo & 0,0536 \\
\hline Freezer funcionando & 1,0000 \\
\hline Quantidade suficiente de mesa & 0,1237 \\
\hline Mesa conservada & 0,4414 \\
\hline Quantidade suficiente de faca & 0,8474 \\
\hline Faca resistente & 0,4414 \\
\hline Faca Limpa & 0,3359 \\
\hline Quantidade suficiente de afiador & 1,0000 \\
\hline Afiador resistente & $0,0181 *$ \\
\hline Afiador limpo & $0,0052 *$ \\
\hline Quantidade suficiente de descamador & 1,0000 \\
\hline Descamador resistente & 0,5316 \\
\hline Descamador limpo & 0,6767 \\
\hline Descamador adequado ao trabalho & 0,5316 \\
\hline Tábua de corte limpa & $0,0179 *$ \\
\hline Tábua de corte conservada & 0,0757 \\
\hline Quantidade suficiente de tábua de corte & 1,0000 \\
\hline Tábua de corte adequada ao trabalho & $0,0031 *$ \\
\hline Caixa de isopor limpa & 0,4669 \\
\hline Caixa de isopor conservada & 0,8084 \\
\hline Caixa de isopor adequada ao trabalho & 0,8084 \\
\hline Roupa adequada & $0,0124 *$ \\
\hline Roupa conservada & 0,0543 \\
\hline Lavagem das mãos antes da manipulação & $0,0071 *$ \\
\hline Lavagem das mãos por qualquer situação & $0,0209 *$ \\
\hline Recebe o dinheiro & 0,2482 \\
\hline
\end{tabular}

*Diferença estatística significativa $(p<0,05)$. 
Quanto à roupa adequada, entre E1 e E3 [respectivamente $7,5 \%(n=3)$ e $40 \%(n=16)$ ] observou-se aumento de conformidades com a legislação vigente, com diferença estatisticamente significativa (Tabela 1). Essa modificação foi importante porque, conforme Brasil (1997), o manipulador de alimentos deve usar vestuário adequado, além de excelente higiene pessoal. No entanto, prevalecem feirantes sem vestimenta adequada e necessários equipamentos de proteção individual, fato que, conforme Brasil (1978), compromete a segurança e saúde do trabalhador. Ainda, de acordo com Freire et al. (2011), não se garante a qualidade do produto à venda e a isenção de microrganismos patogênicos provenientes de contaminação cruzada.

Segundo relatos dos feirantes de Santarém, as temperaturas da cidade e da feira desfavorecem o uso da vestimenta adequada ao trabalho (máscara, gorro, jaleco com mangas longas sobreposto com avental plástico, entre outros elementos), similar a situação e justificativa constatadas nos principais locais de venda de pescado em Bragança-PA e São Luís-MA, por Freire et al. (2011) e Alves; Teófilo (2016), respectivamente.

Em Brasil (2005), consta que o controle de temperatura merece atenção especial pela indústria de alimentos, pois garante a inocuidade e qualidade dos produtos. Ainda, Brasil (1990) recomenda um índice de temperatura efetiva entre $20^{\circ} \mathrm{C}$ e $23^{\circ} \mathrm{C}$ para locais de execução das atividades que exijam solicitação intelectual e atenção constante. Sugere-se a instalação de um ambiente climatizado, cabendo essa adequação ao órgão municipal responsável.

Em E1, pela perspectiva dos feirantes, a lavagem das mãos "antes da manipulação" e "por qualquer situação" era devidamente cumprida $(95 \%$ e $100 \%$, respectivamente). Em contraste, na perspectiva do pesquisador, essa ação era indevidamente cumprida (50\% $[\mathrm{n}=20]$ e $52,5 \% \quad[\mathrm{n}=21]$, respectivamente), pois foram visualizados feirantes manipulando peixe imediatamente após manipulação do dinheiro, entre outras situações agravadas por um dos locais pesquisados não dispor de fornecimento regular de água potável.

Em mercados públicos de Recife-PE, apesar de disporem de água encanada, a frequente indisponibilidade de torneiras era a justificativa para $84 \%$ dos feirantes (re)utilizarem águas em baldes (SOUZA et al., 2016). Algumas feiras na Paraíba também continham boxes sem fornecimento de água, dificultando eventual limpeza e higienização dos manipuladores (CAVALCANTI et al., 2016).

Semelhante a Santarém, a manipulação de dinheiro foi contatada em feirantes no Mercado do Peixe em Bragança-PA (MEDEIROS JUNIOR et al., 2015) e no Mercado Público de Russas-CE (SOBRAL et al., 2013). Porém, de acordo com Brasil (2004), a manipulação de dinheiro ou a prática de outros atos que possam contaminar o alimento durante o desempenho das atividades não deve ser realizada.

Dessa forma, para Santarém se sugere um indicativo de potenciais perigos transferidos ao peixe (e consequentemente, ao consumidor) associado à manipulação de cédulas pelo feirante, conforme a pesquisa de Pêgas et al. (2015) em Volta Redonda-RJ, que constatou alto índice de contaminação do dinheiro manipulado em uma cantina universitária.

Após E2, notou-se uma modificação positiva estatisticamente significativa $(p<0,05)$ relacionada à higiene das mãos (Tabela 1), pois $85 \%(\mathrm{n}=34)$ passaram a praticar as lavagens das mãos "antes da manipulação" e $82,5 \%(\mathrm{n}=33)$ "por qualquer situação”. Legalmente, Brasil (1997) ressalta que manipuladores de alimentos devem, enquanto em serviço, lavar as mãos por qualquer situação, frequente e cuidadosamente, com agente de limpeza autorizado e água corrente potável somente fria ou, primeiro fria e depois quente.

Comparar as perspectivas entre feirantes e pesquisador nas etapas E1 e E3 dessa ação extensionista (isoladamente, Tabelas 2 e 3) serve como um indicador da criticidade, conscientização e adequação dos feirantes de suas ações ao legalmente preconizado. Dessa forma, somente "freezer limpo" e "quantidade suficiente de mesa" (ambos em E1, Tabela 2) e "quantidade suficiente de mesa" [igual E1], lavagem das mãos "antes da manipulação" e "por qualquer situação" (todos em E3, Tabela 3) não diferiram estatisticamente, predominando entre os feirantes as demais atitudes em desacordo com as recomendações legais. Em sua maioria, os feirantes se consideram em conformidade com a legislação vigente, apesar do fato contrário.

Conclui-se que há carência de conhecimento dos feirantes sobre as condições ideais para a comercialização adequada dos peixes em Santarém.

$\mathrm{Na}$ presente ação, informou-se aos feirantes que os peixes deveriam ser idealmente visualizados pelos consumidores através de expositores. Porém, esses feirantes salientaram que o alto valor dos equipamentos e o pouco espaço disponível ao trabalho inviabilizavam sua aquisição.

Similar ao constatado nessa ação, feiras e mercado público de Bragança-PA necessitavam de reformas urgentes e modificadoras de suas estruturas, para se adequar a correta venda de pescado (MEDEIROS JÚNIOR et al., 2015). Também no mercado público Igarapé das Mulheres-AP, o espaço reduzido das bancas atrapalha a manipulação dos produtos, tornando o local desorganizado (SILVA JUNIOR et al., 2016).

Alguns países latinos apresentam boa higienização (não detectada nessa pesquisa) e algumas similaridades quando comparados às feiras de pescado de Santarém. Conforme Tonacca et al. (2013), em Quinta Normal, Chile, os feirantes não estavam bem uniformizados. Em Rivera, Uruguai, apesar da infraestrutura adequada, poucas unidades refrigeradoras foram constatadas (HENDERSON VON-DER PÜTTEN; VARELA SOSA, 2013). Já em Monteria, Colômbia, a infraestrutura e equipamentos não estavam adequadamente conservados e os feirantes desconhecem as Boas Práticas de Manipulação de Alimentos (DURÁN et al., 2014). Em Porto Aurora, Equador, apesar da boa conformidade legal da manipulação pelos feirantes, falhas importantes ainda foram detectadas (ESPAÑA, 2016). 
Nessa pesquisa, ressalta-se especialmente a lavagem das mãos "antes da manipulação" e "por qualquer situação", pois apresentou opiniões divergentes e legalmente negativas em E1 (Tabela 2), mas semelhantes e positivas em E3 (Tabela 3 ).

Tabela 2. Valores de significância $(p)$ referentes aos elementos analisados na comparação entre a perspectiva do feirante e pesquisador sobre elementos analisados na etapa 1 .

\begin{tabular}{|c|c|}
\hline Elementos Analisados & Valor de $p$ \\
\hline Balança limpa & $0,0124 *$ \\
\hline Balança funcionando & 1,0000 \\
\hline Freezer funcionando & $<0,0001 *$ \\
\hline Freezer limpo & 0,3346 \\
\hline Quantidade suficiente de mesa & 0,8474 \\
\hline Mesa conservada & $0,0124 *$ \\
\hline Quantidade suficiente de faca & 1,0000 \\
\hline Faca resistente & $0,0011 *$ \\
\hline Faca Limpa & $<0,0001 *$ \\
\hline Quantidade suficiente de afiador & 1,0000 \\
\hline Afiador resistente & $<0,0001 *$ \\
\hline Afiador limpo & $<0,0001 *$ \\
\hline Quantidade suficiente de descamador & 1,0000 \\
\hline Descamador resistente & $<0,0001 *$ \\
\hline Descamador limpo & $<0,0001 *$ \\
\hline Descamador adequado ao trabalho & $<0,0001 *$ \\
\hline Tábua de corte limpa & $<0,0001 *$ \\
\hline Tábua de corte conservada & $<0,0001 *$ \\
\hline Quantidade suficiente de tábua de corte & 1,0000 \\
\hline Tábua de corte adequada ao trabalho & $<0,0001 *$ \\
\hline Caixa de isopor limpa & $<0,0001 *$ \\
\hline Caixa de isopor conservada & $<0,0001 *$ \\
\hline Caixa de isopor adequada ao trabalho & $<0,0001 *$ \\
\hline Roupa adequada & $<0,0001 *$ \\
\hline Roupa conservada & $<0,0001 *$ \\
\hline Lavagem das mãos antes da manipulação & $0,0005 *$ \\
\hline Lavagem das mãos por qualquer situação & $0,0003 *$ \\
\hline Recebe o dinheiro & 1,0000 \\
\hline
\end{tabular}

* Diferença estatística significativa $(p<0,05)$.
Tabela 3. Valores de significância $(p)$ referentes aos elementos analisados na comparação entre a perspectiva do feirante e pesquisador sobre elementos analisados na etapa 3.

\begin{tabular}{|c|c|}
\hline Elementos Analisados & Valor de $p$ \\
\hline Balança limpa & $* 0,0093$ \\
\hline Balança funcionando & 1,0000 \\
\hline Freezer funcionando & 1,0000 \\
\hline Freezer limpo & $* 0,0067$ \\
\hline Quantidade suficiente de mesa & 0,1237 \\
\hline Mesa conservada & $* 0,0039$ \\
\hline Quantidade suficiente de faca & 1,0000 \\
\hline Faca resistente & $* 0,0003$ \\
\hline Faca Limpa & $* 0,0011$ \\
\hline Quantidade suficiente de afiador & 1,0000 \\
\hline Afiador resistente & $* 0,0010$ \\
\hline Afiador limpo & $*<0,0001$ \\
\hline Quantidade suficiente de descamador & 1,0000 \\
\hline Descamador resistente & $*<0,0001$ \\
\hline Descamador limpo & $*<0,0001$ \\
\hline Descamador adequado ao trabalho & $*<0,0001$ \\
\hline Tábua de corte limpa & $*<0,0001$ \\
\hline Tábua de corte conservada & $*<0,0001$ \\
\hline Quantidade suficiente de tábua de corte & 1,0000 \\
\hline Tábua de corte adequada ao trabalho & $* 0,0035$ \\
\hline Caixa de isopor limpa & 0,0006 \\
\hline Caixa de isopor conservada & $*<0,0001$ \\
\hline Caixa de isopor adequada ao trabalho & $*<0,0001$ \\
\hline Roupa adequada & $* 0,0021$ \\
\hline Roupa conservada & $* 0,0005$ \\
\hline Lavagem das mãos antes da manipulação & 0,2482 \\
\hline Lavagem das mãos por qualquer situação & 0,3359 \\
\hline Recebe o dinheiro & 1,0000 \\
\hline
\end{tabular}

Desse modo, é possível perceber que as instruções repassadas aos feirantes nessa ação extensionista resultaram em melhorias, apesar de ainda se perceberem majoritária continuidade das inadequações nas atividades. Essas poucas modificações demonstram a importância e eficácia de ações educativas, desde que associadas à continuidade e insistência das mesmas junto aos feirantes, ainda em parceria com os órgãos 
fiscalizadores e a readequação estrutural por parte do órgão municipal responsável, todos seriamente trabalhando para o bem estar comum.

\section{Conclusões}

Nas feiras de Santarém são encontradas diversas irregularidades na comercialização de pescado. No entanto, as ações educativas e de conscientização se mostraram eficientes sobre alguns aspectos, pois promoveram mudanças positivas na comercialização de peixes nas feiras. Algumas modificações necessárias não foram visualizadas devido à infraestrutura atual das feiras não favorecê-las, conforme justificativas plausíveis dos feirantes. Portanto, ainda há a necessidade de melhorias, sendo algumas de responsabilidade dos feirantes, e outras a serem solucionadas pelo órgão municipal responsável.

\section{Agradecimentos}

Aos feirantes da Feira do Pescado e Mercadão 2000, pela gentileza e confiança ao participarem voluntariamente das etapas essenciais desse trabalho. Também ao apoio institucional (reconhecimento desse projeto de extensão e concessão de bolsa de iniciação à extensão) da PróReitoria da Cultura, Comunidade e Extensão da Universidade Federal do Oeste do Pará. À Alcione Deodato, pela revisão gramatical.

\section{Contribuição de cada autor}

Os autores elaboraram, executaram o projeto e redigiram o texto aqui apresentado. Especialmente, T. M. S., bolsista de extensão universitária, contribuiu com as análises estatísticas, enquanto H. M. A. atuou como coordenador e orientador dessa ação extensionista.

\section{Referências}

ALCÂNTARA, G. L. C.; KATO, H. C. A. Boas práticas de manipulação na comercialização do camarão fresco em feiras livres de Belém, PA. Journal of Bioenergy and Food Science, v. 3, n. 3, p. 139-148, 2016.

ALMEIDA, J. F. C.; SOUZA, T. M.; MENDONÇA, X. M. D. F. Avaliação sensorial de peixes comercializados em dois mercados públicos de Santarém-PA. In: XIX CONGRESSO BRASILEIRO DE ENGENHARIA DE PESCA, 2015, São Luís. Resumos... Maranhão: Associação Brasileira dos Engenheiros de Pesca, 2015.

ALMEIDA, M. D.; PENA, P. G. L. Feira livre e risco de contaminação alimentar: estudo de abordagem etnográfica em Santo Amaro. Revista Baiana de Saúde Pública, v. 35, n. 1, p. 110-127, 2011.

ALVES, G. L.; TEÓFILO, T. S. Aspectos higiênicosanitários de estabelecimentos de comercialização de pescado no "Mercado do peixe" em São Luís-MA.
Revista Científica de Medicina Veterinária, n. 26, 2016.

AMAZONAS, T. M. M. Informações municipais de Santarém. Secretaria Municipal de Meio Ambiente Centro Municipal de Informações Ambientais, Santarém, PA, 2013.

BERTOLO, A. P.; LANÇANOVA, D.; MUZZOLON, E; TRENTO, A.; BAINY, E. M.; DOS PASSOS, C. T.Experiência do uso das Boas Práticas de Fabricação para melhoria das condições higiênico-sanitárias da Feira do Agricultor de Laranjeiras do Sul - PR. Revista Brasileira de Extensão Universitária, v. 7, n. 1, p. 5157, 2016.

BRANDÃO, B. P.; VINENTE NETO, B. F.; PONTES, D. F.; CARVALHO, J. A. S.; LEAL, J. F. S.; QUARESMA, T. C. Agravantes ambientais que influenciam na carne e no pescado do Mercado Municipal de Santarém-PA. Em Foco, Ano 11, n. 21, 2014.

BRASIL. Ministério do Trabalho e Emprego. Portaria GM n. ${ }^{\circ}$ 3.214, de 08 de junho de 1978. Norma Regulamentadora 6 - Equipamento de Proteção Individual - EPI. Diário Oficial da União, 1978.

BRASIL. Ministério do Trabalho e Emprego. Portaria n. ${ }^{\circ}$ 3.751, de 23 de novembro 1990. Norma Regulamentadora 17 - Ergonomia. Diário Oficial da União, 1990.

BRASIL. Ministério da Saúde. Portaria no 326, de 30 de julho de 1997. Dispõe sobre Regulamento Técnico de Condições Higiênico-Sanitárias e de Boas Práticas de Fabricação para estabelecimentos Produtores/ Industrializadores de Alimentos. Diário Oficial da União, 1997.

BRASIL. Ministério da Saúde. Agência Nacional de Vigilância Sanitária. RDC no 275, de 21 de outubro de 2002. Dispõe sobre o Regulamento Técnico de Procedimentos Operacionais Padronizados aplicados aos Estabelecimentos Produtores/Industrializadores de Alimentos e a Lista de Verificação das Boas Práticas de Fabricação em Estabelecimentos Produtores/ Industrializadores de Alimentos. Diário Oficial da União, S. 1, p. 126, 23 set. 2003.

BRASIL. Ministério da Saúde. Agência Nacional de Vigilância Sanitária. RDC no 216, de 15 de setembro de 2004. Dispõe sobre Regulamento Técnico de Boas Práticas para Serviços de Alimentação. Diário Oficial da União, S. 1, n. 179, p. 25, 16 set. 2004.

BRASIL. Ministério da Agricultura, Pecuária e Abastecimento Mapa. Departamento de Inspeção de Produtos de Origem Animal - DIPOA. Circular n. 175, de 16 de maio de 2005. Dispõe sobre Procedimentos de Verificação dos Programas de Autocontrole. 2005. Disponível em < http://www.fooddesign.com.br/ arquivos/legislacao/Circular\%20175-05\%20PPHO\%20 para\%20frigorifico\%20FD.pdf $>$, acesso em 02 out 2017.

CAMPOS, D. S.; PAIVA, Z. C. Condição higiênicosanitária do pescado comercializado em feira no município de Manaus - AM. Caderno de PósGraduação da FAZU, v. 3, 2012. 
CAMPOS, I. F.; DA SILVA, E. M. M.; DE PAULA, A. H.; BARBOSA, W. M. Condições higiênico-sanitárias do peixe peroá (Balistes capriscus) comercializado no Mercado Municipal de Guarapari (ES), antes e após intervenção. Revista da Associação Brasileira de Nutrição, v.7, n. 2, p. 56-65, 2016.

CAVALCANTI, C. R. PAULINO, F. O.; MAYER, K. D. G.; DA SILVA, F. F., GOMES, V. D. S., SANTOS, F. G. A. Avaliação e diagnóstico das condições de comercialização de alimentos nas feiras livres no estado da Paraíba. Arquivos de Ciências Veterinárias e Zoologia da UNIPAR, v. 17, n. 3, p. 167-172, 2014.

DURÁN, E.; ROSADO, R. R.; BALLESTEROS, O. D.; LERMA, D. E. Comercialización de pescado en las principales plazas de mercado de Montería, Colombia. Temas Agrarios, v. 19, n. 1, p. 48-62, 2014.

ESPAÑA, L. L. Análisis de las condiciones de higiene, manipulación y expendio de alimentos en el mercado municipal de Puerto Ayora, Isla Santa Cruz, y su incidencia en el nivel de consumo entre los servicios turísticos locales, como un modelo dirigido a la aplicación de las buenas prácticas y normas técnicas de calidad. Trabalho de conclusão de curso, Facultad de Agronomía, Universidad Central del Ecuador Sede Galápagos, 2016.

FREIRE, J. L.; SILVA, B. B.; SOUZA, A. S. Aspectos econômicos e higiênico-sanitários da comercialização do pescado no municipio de Bragança (PA). Biota Amazônia, v. 1, n. 2, p. 17-28, 2011.

HENDERSON VON-DER PÜTTEN, B. V.; VARELA SOSA, L. S. Caracterización de la venta y condiciones higienico-sanitarias del pescado comercializado en la ciudad de Rivera. Tese de Doutorado, Facultad de Veterinaria, Universidad de la República, Montevideo, Uruguai, 2013.

LEANDRO, S. V.; OTANI, F. S.; SOUSA, J. E. M.; PAULA, T. C. P. Perfil de Consumo e Consumidor de Pescado no município de Santarém, Pará. In: XXV CONGRESSO BRASILEIRO DE ZOOTECNIA, 2015, Fortaleza. Resumos... Ceará. Associação Brasileira dos Zootecnistas, 2015.

MEDEIROS JUNIOR, E. F.; EIRAS, B. J. C. F.; RODRIGUES, E. C.; ALVES, M. M. Avaliação higiênico-sanitária do pescado comercializado na cidade de Bragança Pará. Revista Eletrônica Nutritime, v. 12, n. 5, p. 4237-4243, 2015.

OMS - ORGANIZAÇÃO MUNDIAL DA SAÚDE. Segurança básica dos alimentos para profissionais da saúde. São Paulo: Roca, 2002. Disponível em: s http://apps.who.int/iris/bitstream/10665/65992/2WHO_SDE_P HE_FOS_99.1_por.pdf $>$ Acesso em: $14 \mathrm{fev} 2017$.

PÊGAS, S. S.; RABELLO, B.; KAWAKAMI, E. M.; MELlO, F. A.; PEREIRA, C. A. S. Avaliação da contaminação por bactérias em cédulas e moedas circulantes em cantina do Centro Universitário de Volta Redonda - UniFOA. Cadernos UniFOA, n. 27, p. 75 $81,2015$.

SANTOS, L. L. M. P.; MENDES, M. A.; CALAFANGE, R. M.; LIMA, S. M. S. Condições higiênico-sanitárias das carnes aves e pescados comercializados na feira central de Campina Grande PB: Percepções dos comerciantes x realidade. SCIRE Revista Acadêmico-Cientifica, v. 6, n. 2, p. 1-9, 2014.

SILVA JUNIOR, A. C. S.; BARBOSA, F. H. F.; MONTEIRO, J. F. Aspectos higiênico-sanitários na comercialização no Mercado de Pescado Igarapé das Mulheres, Macapá-AP. Biota Amazônia, v. 6, n. 4, p. 15-19, 2016.

SOBRAL, R. R. M.; BATISTA, R. S. A.; NACIMENTO, C. P.; NUNES, E. N.; SILVA, A. P. V. Avaliação das condições higiênico-sanitárias no mercado público de Russas, Ceará. Revista Agropecuária Técnica, v. 34, n. 1, p 30-39, 2013.

SOUZA, E. R. S.; BATISTA, P. K.; VASCONCELOS, R. G.; PONTES, M. M. N.; SILVA, G. F.; AQUINO, R. C. A. Boas Práticas de Manipulação de Pescados em Mercados Públicos do Recife-PE. Revista Eletrônica da Estácio Recife, v. 1, n.1, p. 1-10, 2016.

SOUZA, T. S.; BENTES, G. J. F.; SANTOS-JUNIOR, L. M.; SANTOS, P. R. B.; ATAYDE, H. M. Preferência do consumo e procedência de peixes em Santarém, Pará. In: XIX CONGRESSO BRASILEIRO DE ENGENHARIA DE PESCA, 2015. São Luis: Resumos... Maranhão: Associação Brasileira dos Engenheiros de Pesca, 2015.

TONACCA, L. S.; RUIZ, L. C.; RAMÍREZ, C. D. Evaluación de la satisfacción de clientes respecto de la calidad de atención en la Feria Libre $N^{\circ} 2$ de la comuna de Quinta Normal, Santiago de Chile. Idesia , v. 31, n. 2, p. 15-23, 2013.

YAMAMOTO, N. S.; BRANCO, C. P.; SANTOS, J. L. Avaliação qualitativa do pescado comercializado no município de Santos. Revista Ceciliana, v. 4, n. 1, p. 7277, 2012.

\footnotetext{
Como citar este artigo:

SOUZA, T. M. de; ATAYDE, H. M. Educação higiênicosanitária dos feirantes do Mercadão 2000 e Feira do Pescado em Santarém-PA. Revista Brasileira de Extensão Universitária, v. 8, n. 3, p. 127-134, 2017. Disponível em: < https://periodicos.uffs.edu.br/index.php/RBEU/article/view/502 $\underline{8 / p d f}>$
} 